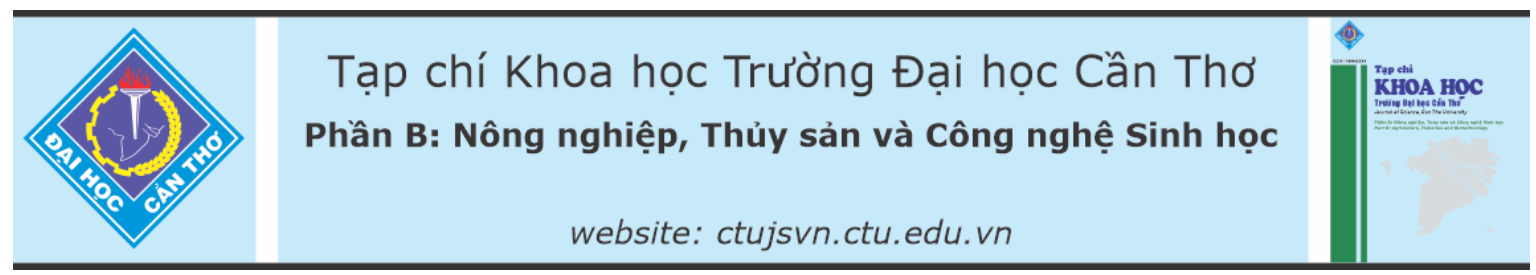

DOI:10.22144/ctu.jvn.2021.189

\title{
ÚNG DỤNG DẤU CHİ THỊ PHÂN TỬ SSR TRONG CHỌN GIỐNG LÚA MANG KIỂU GENE CHỐNG CHỊU MậN VÀ PHẨM CHẤT Ở 20 GIỐNG/DÒNG LÚA CẢI TIẾN
}

\author{
Nguyễn Văn Mạnh ${ }^{1}$, Trần In Đô ${ }^{1}$, Văn Quốc Giang ${ }^{2}$, Huỳnh Như Điền ${ }^{2}$, Lê Thị Hồng Thanh ${ }^{2}$ và \\ Huỳnh $\mathrm{Kỳ}^{2 *}$ \\ ${ }^{1}$ Học viên cao học, Bộ môn Di truyền và Chọn giống Cây trồng, Khoa Nông nghiệp, Truờng Đại học Cần Tho \\ ${ }^{2}$ Bộ môn Di truyền và Chọn giống Cây trồng, Khoa Nông nghiệp, Trường Đại học Cần Tho \\ *Nguoòi chịu trách nhiệm về bài viết: Huỳnh Kỳ (email: hky@ctu.edu.vn)
}

\section{Thông tin chung:}

Ngày nhận bài: 11/05/2021

Ngày nhận bài sưa: 10/06/2021

Ngày duyệt đăng: 25/12/2021

Title:

Application of SSRs markers for selecting salt tolerance and quality genotype from 20 improved rice varieties/lines

\section{Tù khóa:}

Chống chịu mặn, lúa cải tiến, SSR

Keywords:

MTL, salt, QTL, SSR

\section{ABSTRACT}

Salinity intrusion has affected (caused reduces in) rice yield and quality because rice is very sensitive to salinity. In this study, SSR markers were applied to test 20 improved rice varieties for salinity tolerance and quality (grain length and amylose content) characteristics. These 12 SSR molecular markers were linked to Quantitative Trait Loci (QTL) for salt tolerance on 12 comparable chromosomes for comparision the geneotype between the standard salt tolerance variety (Doc Phung) and the salt sensitive standard variety (IR29) with 20 improved rice varieties at Can Tho University. The results showed that there were 3 varieties with geneotypes similar to the standard varieties of salt tolerance (Doc Phung) with P1000 from 29 to 32 grams, with long grain and low amylose content $(17.64 \%)$ in the variety MTL 859 , the average amylose content $(22.70 \%$ and $24.52 \%)$ in the varieties MTL 421 and MTL 743, respectively. In addition, there were two varieties/lines MTL 421 and MTL 859 with the aromatic characteristic at level 2 based on the $\mathrm{KOH} \mathrm{1,7 \%} \mathrm{test} \mathrm{method.} \mathrm{This} \mathrm{result} \mathrm{is} \mathrm{the} \mathrm{basis} \mathrm{for} \mathrm{further} \mathrm{studies} \mathrm{on} \mathrm{improved}$ rice varieties with salt tolerance in the future.

\section{TÓM TẮT}

Việc xâm nhiễm mặn đã ảnh hưởng lên cây lúa, làm giảm năng suất và chất luợng lúa, vì cây lúa rất mẫn cảm với mặn. Vì vây, trong nghiên cứu này, dấu chỉ thị phân tử SSR được sư dụng trong chọn giống lúa mang kiểu gene chống chịu mặn và mang đặc tính phẩm chất ở 20 giống lúa cải tiến. Nghiên cứu đãa đánh giá khối lương 1.000 hạt, chiều dài hạt gạo, hàm luợng amylose. Bên cạnh đó, 12 dấu phân tử SSR liên kết với tính trạng số lượg (QTL) mang nhũng kiểu gene chịu mặn nằm trên 12 nhiễm sắc thể (NST) được sử dụng để so sánh kiểu gene giũa giống chuẩn chống chịu mặn (Đốc Phụng) và giống chuẩn mẫn cảm mặn (IR29) với 20 giống lúa cải tiến tại Truờng Đại học Cần Tho: Kết quả cho thấy 3 giống lúa được chọn mang kiểu gene tuơng đồng với giống chuẩn chống chịu mặn (Đốc Phụng) và 3 giống này đều có dạng hạt thon dài. Hàm luợng amylose thấp $(17,64 \%)$ ở giống MTL 859, hàm lương amylose trung bình (22,70\% và 24,52\%) ở giống MTL 421 và MTL 743. Hai giống MTL 421 và MTL 859 mang kiểu gene thơm và có mùi thơm cấp 2 qua phuơng pháp thử $\mathrm{KOH} 1,7 \%$. Kết quả này là cơ sở cho các nghiên cứu tiếp theo về các giống lúa cải tiến có khả năng chịu mặn trong tuơng lai. 


\section{1. ĐặT VẤN ĐỀ}

Dân số thế giới được dự báo sẽ tăng lên 9 tỷ người vào năm 2050, do đó thì sản lượng gạo của thế giới phải tăng từ $25-70 \%$ để đáp ứng nhu cầu do sự gia tăng dân số dự kiến (Mitchell et al., 2017). Tuy nhiên, tình trạng đất bị nhiễm mặn và môi trường sinh thái bị suy thoái đang thách thức năng suất nông nghiệp và an ninh lương thực, việc cải thiện khả năng chịu mặn của cây lúa sẽ làm tăng khả năng sử dụng tiềm năng đất mặn-kiềm để canh tác lúa và là một trong những giải pháp hữu hiệu để có thể giải quyết được vấn đề lương thực (Qin et al., 2020). Điều này đòi hỏi phải xác định hoặc lai tạo các giống lúa mới có khả năng phát triển ở các vùng đất ven biển và trong môi trường bất lợi. Tuy nhiên, việc chọn tạo ra giống lúa có khả năng chống chịu mặn còn phụ thuộc vào nhiều yếu tố như cần phải làm rõ cơ chế chống chịu stress của cây lúa (Kurotani et al., 2015) thông qua việc phân tích đồng thời các yếu tố khác nhau: phản ứng sinh lý, biến đồi gene, thay đổi bộ gene và những cơ chế phân tử (Ganie et al., 2019); xác định các locus tính trạng số lượng và các dấu hiệu liên kết với các QTL quan trọng. Từ trước đến nay, đã có nhiều nghiên cứu sâu rộng về lập bản đồ QTL đối với khả năng chịu mặn của cây lúa nhưng có rất ít QTL có thể được áp dụng hiệu quả trong chọn tạo giống thực tế. Nhưng điều này vẫn mang lại giá trị lớn trong việc xác định các QTL chịu mặn hoặc các gene có liên quan trong nguồn gene ưu tú và áp dụng để chọn tạo ra giống mới (Wu et al., 2020).

Saltol là một QTL chính chống chịu mặn ở giai đoạn mạ (Yadav et al., 2020). QTL Saltol thuộc NST số 1 được phát hiện từ quần thể lai giữa giống lúa IR29 (nhạy cảm) và giống lúa Pokkali (chống chịu), QTL Saltol kiểm soát khả năng hấp thu $\mathrm{Na}^{+} / \mathrm{K}^{+}$. Cân bằng $\mathrm{Na}^{+} / \mathrm{K}^{+}$trong nội mô chồi và giải thích từ $64,3 \%$ đến $80,2 \%$ sự thay đổi của kiểu hình ở khả năng chịu mặn trên cây lúa (Bonilla et al., 2002; Mohammadi-Nejad et al., 2008). Nhóm nghiên cứu Lin et al. (2004) dựa trên kết quả phân tích mối tương quan giữa khả năng sinh trưởng của cây con (survival days of seedlings (SDSs)) và các đặc điểm sinh lý phức tạp liên quan đến khả năng chịu mặn trên cây lúa dưới tác động của mặn trên quần thể lai giữa giống Indica (Nona Bokra-giống chống chịu) và giống japonica (Kashihikari-giống nhạy cảm) cho rằng sự tổn thương của lá do sự tích lũy $\mathrm{Na}^{+}$trong chồi cao bởi sự vận chuyển $\mathrm{Na}^{+}$từ rễ đến chồi khi nồng độ $\mathrm{Na}^{+}$bên ngoài cao. Ghi nhận 2 QTL có ảnh hưởng rất lớn, qSNC-7 đối với nồng độ $\mathrm{Na}^{+}$ở chồi và qSK-1 đối với nồng độ $\mathrm{K}^{+}$ở chồi giải thích lần lượt là $48,5 \%$ và $40,1 \%$ tổng phương sai kiểu hình. Các QTL được phát hiện giữa chồi và rễ hầu như không có cùng vị trí trên bản đồ di truyền, các gene kiểm soát sự vận chuyển $\mathrm{Na}^{+}$và $\mathrm{K}^{+}$giữa chồi và rễ có thể khác nhau (Lin et al., 2004). Một QTL khác cũng đã được báo cáo là qSNC11, qSNC11 được xác định làm giảm nồng độ $\mathrm{Na}^{+}$ở chồi, đóng vai trò quan trọng trong khả năng chịu mặn của lúa và có thể được sử dụng để cải thiện khả năng chịu mặn của các giống lúa thương mại bằng phương pháp chọn lọc hỗ trợ bằng chỉ thị phân tử (MAS) (Wang et al., 2012).

Hiện nay, việc cải thiện khả năng chống chịu điều kiện bất lợi của lúa mà ít ảnh hưởng đến năng suất và chất lượng là một thách thức đối với các nhà chọn tạo giống (Qin et al., 2020). Vì năng suất và chất lượng là hai tiêu chí quan trọng nhằm đảm bảo an ninh lương thực trong và ngoài nước. Để đáp ứng nhu điều kiện trên, ứng dụng dấu chỉ thị phân tử hỗ trợ trong chọn giống (marker-assisted breeding$\mathrm{MAB})$ là một trong những lựa chọn hàng đầu trong việc đánh giá đa dạng di truyền, hồ trợ nhận diện các QTL và các dấu hiệu liên kết với khả năng chịu mặn của cây lúa (Ganie et al., 2019). Trong đó, Simple Sequence Repeats (SSR) là marker phân tử liên kết chặt với QTL saltol, do đó việc ứng dụng dấu phân tử SSRs cho chọn giống lúa chịu mặn giúp cho công tác chọn giống hiệu quả hơn. Xuất phát từ nhu cầu thực tiễn đó nghiên cứu này được thực hiện, nhằm tìm ra một số giống mang kiểu gene chịu mặn tối ưu và có năng suất chất lượng cao để làm nền tảng tiếp theo trong chọn giống chịu mặn có triển vọng.

\section{VậT LIẾU VÀ PHƯƠNG PHÁP NG̈HIÊN CÚU}

\subsection{Vật liệu nghiên cứu}

Nguồn gốc của 20 giống lúa cải tiến MTL được chọn tạo tại Viện Nghiên cứu và Phát triển Đồng bằng sông Cửu Long (MDI) và hiện đang tồn trữ tại ngân hàng giống Khoa Nông nghiệp, Trường Đại học Cần Thơ. 
Bảng 1. Danh sách các giống lúa được nghiên cứu

\begin{tabular}{cllll}
\hline STT & Tên giống & Gia phả (nguồn gốc) & Cây cha & Cây mẹ \\
\hline 1 & Đốc Phụng & Bình Đại-Bến Tre & & \\
2 & MTL 232 & IR65623-249-2-3-2-3 & IR59606 & IR60819 \\
3 & MTL 279 & L251-2-5-2-1 & VD10 & IR64 \\
4 & MTL 421 & L280-10-12-2-2-2-1-1 & MTL156 & Khaohom \\
5 & MTL 470 & L318-1-2-4-3-2-2-1-1 & MTL156 & Khaohom \\
6 & MTL 568 & L318-1-4-2-6-1-3-2-1 & LTCN & OM1723 \\
7 & MTL 579 & L274-4-5-1-2-7-1-1-1 & MTL241 & MTL142/LTCN \\
8 & MTL 591 & L353-17-20-2-1-2 & CK96/IR64 & MTL241 \\
9 & MTL 660 & L351-3-1-3-1-1-2-1 & MTL352 & MTL325 \\
10 & MTL 684 & L485-2-2-3-2-2-1-2 & Amaroo & MTL364 \\
11 & MTL 685 & L456-2-1-2-2-2-1-1- & MTL352 & MTL325 \\
12 & MTL 736 & L485-2-10-4-2-2-3-3-1-2 & OM1490 & Nếp Thái Lan \\
13 & MTL 743 & L474-6-3-5-2-1-2 & MTL352 & MTL325 \\
14 & MTL 772 & L485-3-10-4-1-2-3-11-1-10 & Amaroo & VD20 \\
15 & MTL 773 & L455-1-9-1-3-3-11-2-2 & Jasmin85 & MTL98 \\
16 & MTL 834 & T3-2-2-3-1-1-4-1-1 & MTL 250 & MTL 463 \\
17 & MTL 856 & L518-6-2-1-1-2-1 & MTL 250 & MTL 463 \\
18 & MTL 857 & L518-6-11-1-1-2-1 & MTL 250 & MTL 463 \\
19 & MTL 859 & L518-6-11-1-1-3-1 & MTL145 & MTL250 \\
20 & MTL 883 & L520-2-9-1-4-3-2-1 & OM1490 & Nếp Thái Lan \\
21 & MTL 889 & L474-6-2-1-2-1 & & \\
22 & IR29 & Viện Nghiên cứu Lúa Quốc tế (IRRI) & & \\
\hline
\end{tabular}

\subsection{Phương pháp nghiên cứu}

\subsection{1. Đánh giá các đặc tính nông học}

Phân tích các chỉ tiêu chất lượng: Chiều dài gạo, chiều rộng gạo dựa trên tiêu chuẩn IRRI (1996). Phân tích hàm lượng amylose theo phương pháp của Graham (2002), phương pháp phân tích độ bền thể gel và phương pháp đánh giá mùi thơm cảm quan bằng $\mathrm{KOH} 1,7 \%$ kết hợp với kiểm tra kiểu gene $f g r$.

2.2.2. Đánh giá kiểu gene chịu mặn của các giống lúa

Phân tích kiểu gene chịu mặn: DNA của 20 giống lúa được ly trích theo phương pháp $\mathrm{CTAB}$ (Doyle \& Doyle, 1987) có cải tiến. Dung dịch ly trích DNA được sử dụng là CTAB $2 \mathrm{X}(2 \% \mathrm{CTAB}$, $100 \mathrm{mM}$ Tris $\mathrm{pH}$ 8.0, $20 \mathrm{mM}$ EDTA pH 8.0, 1.4 M $\mathrm{NaCl}$ ). Ngoài ra, các chất hỗ trợ cho việc ly trích DNA thêm hiệu quả là $\beta$-mercaptoethanol, chloroform: isoamyl alcohol (24:1), isopropanol, ethanol (70\%). Sau khi trích xong, DNA được hòa tan trong $40 \mu \mathrm{TTE}(\mathrm{pH} 8,0)$ và trữ ở nhiệt độ $-20^{\circ} \mathrm{C}$.
Kiểu gene chịu mặn được đánh giá dựa vào sự liên kết của 12 cặp mồi SSR với các $\mathrm{QTL}$ nằm trên 12 NST theo Lin et al. (2004) và Thomson et al. (2010) bằng kỹ thuật PCR. Phản ứng PCR được thực hiện ở $15 \mu \mathrm{L}$ hỗn hợp $\mathrm{PCR}$, sử dụng dung dịch 2xPCR (MyTaq Bioline, UK) gồm các thành phần 5X MyTaq Buffer, MyTaq DNA Polymerase, thêm vào nước tinh sạch, mồi và $\mathrm{DNA}$. Tất cả được trộn đều trước khi cho vào máy PCR GeneAmp PCR System 2700. Phản ứng PCR được thực hiện trong 35 chu kỳ gia nhiệt, bao gồm: 5 phút ở $95^{\circ} \mathrm{C}, 30$ giây ở $95^{\circ} \mathrm{C}, 30$ giây ở $58-70^{\circ} \mathrm{C}$ (tùy vào nhiệt độ của từng mồi), 30 giây ở $72^{\circ} \mathrm{C}$, kéo dài chuỗi trong 5 phút ở $72^{\circ} \mathrm{C}$ và sản phẩm được trữ ở $10^{\circ} \mathrm{C}$ trong 20 phút và thứ tự của 12 cặp mồi với 12 NST được liệt kê trong Bảng 2. Sau khi điện di, gel được nhuộm với ethidium bromide $(10 \mathrm{mg} / \mathrm{mL})$. Kết quả PCR được ghi nhận dựa vào phổ điện di cho kích thước band trùng khớp với giống đối chứng dương (giống chống chịu), hay giống đối chứng âm (giống mẫn cảm). 
Bảng 2. Danh sách 12 cặp mồi SSR liên kết với các QTL chống chịu mặn nằm trên 12 NST và mồi BADH2 nhận diện gene $f g r$

\begin{tabular}{llllll}
\hline Mồi & Mồi xuôi & Mồi ngược & NST & $\begin{array}{l}\text { Kích } \\
\mathbf{T}_{\mathbf{m}}\end{array}$ & $\begin{array}{l}\text { thước } \\
\text { (bp) }\end{array}$ \\
\hline RM3810 & ACGAAGGAACTACCCGTGTG & CGCACATGTTACTCTAGCGG & 1 & 60 & 105 \\
RM211 & CCGATCTCATCAACCAACTG & CTTCACGAGGATCTCAAAGG & 2 & 58 & 161 \\
RM6329 & CCCTGGATGAAAAGCACAAG & GAAGTTGTAGATGCCCCATC & 3 & 59 & $145 / 125$ \\
RM127 & GTGGGATAGCTGCGTCGCGTCG & AGGCCAGGGTGTTGGCATGCTG & 4 & 69 & 190 \\
RM17749 & ACGCACATCACAACCTCACTGC & TCTCTTGCCACACACCTTACATCC & 5 & 65 & 171 \\
RM253 & TCCTTCAAGAGTGCAAAACC & GCATTGTCATGTCGAAGCC & 6 & 58 & 141 \\
RM214 & CTGATGATAGAAACCTCTTCTC & AAGAACAGCTGACTTCACAA & 7 & 58 & 132 \\
RM6369 & CAAGCTAGGGCTGCATAAGC & GCTTCACCTACCTACCTCACC & 8 & 63 & $120 / 110$ \\
RM24330 & AATCCGCGGGAGCAATCAACC & CGATGACCAATGACGAGGTGAGG & 9 & 65 & $95 / 110$ \\
RM 474 & AAGATGTACGGGTGGCATTC & TATGAGCTGGTGAGCAATGG & 10 & 59 & $285,345 /$ \\
RM 286 & GGCTTCATCTTTGGCGAC & CCGGATTCACGAGATAAACTC & 11 & 58 & 115,260 \\
RM28102 2 CACTAATTCTTCGGCTCCACTTT & GTGGAAGCTCCGAGAAAGTGC & 12 & 64 & 168 \\
& ESP & TTGTTTGGAGCTTGCTGATG & & \\
BADH2 & EAP & ANSP & CTTGCTTTACAAAGTCCCGC & & 50 \\
& IFAP & CATAGGAGCAGCTGAAATATATACC & & \\
\hline
\end{tabular}

\subsubsection{Phương pháp phân tích số liệu}

Phần mềm Excel 2013 được sử dụng để phân tích các chỉ tiêu chất lượng. Kích thước các band DNA đánh giá kiểu gene được tính toán bằng phần mềm GelAnalyzer (Istvan \& Istvan, 2019). Phương pháp UPGMA được sử dụng thông qua phần mềm NTSYS pc 2.1 để tạo nên biểu đồ thể hiện mối liên hệ di truyền.

\subsection{Thời gian và địa điểm nghiên cứu}

Nghiên cứu được thực hiện từ tháng 10 đến tháng 12 năm 2020 tại phòng thí nghiệm Di truyền và Chọn giống cây trồng, Khoa Nông nghiệp, Trường Đại học Cần Thơ.

\section{KẾT QUẢ VÀ THẢO LUẬN}

\section{1. Đánh giá các đặc tính nông học}

Một chỉ tiêu quan trọng trong chọn giống là chiều dài hạt gạo, bởi hiện nay nhu cầu thị trường trong và ngoài nước đa số ưa chuộng hạt gạo thon dài. Theo IRRI (2013), chiều dài gạo được phân nhóm như sau: gạo rất dài $(\geq 7,5 \mathrm{~mm})$, hạt gạo dài $(6,6-7,5 \mathrm{~mm})$, gạo dài trung bình $(5,51-6,6 \mathrm{~mm})$ và gạo ngắn $(\leq 5,5 \mathrm{~mm})$. Tiêu chuẩn của IRRI được sử dụng để đánh giá chiều dài hạt gạo của 20 giống lúa cải tiến. Kết quả cho thấy đa số các giống có chiều dài hạt gạo trên $7 \mathrm{~mm}$ thuộc nhóm hạt gạo dài đến rất dài từ 7,2 đến $8,3 \mathrm{~mm}$.

Bảng 3. Chiều dài gạo của 20 giống lúa được nghiên cứu

\begin{tabular}{clcccr}
\hline STT & Tên giống & Dài gạo (mm) & STT & Tên giống & Dài gạo (mm) \\
\hline 1 & Đốc Phụng & & 12 & MTL 736 & 7,85 \\
2 & MTL 232 & 7,65 & 13 & MTL 743 & 7,35 \\
3 & MTL 279 & 7,75 & 14 & MTL 772 & 7,60 \\
4 & MTL 421 & 7,20 & 15 & MTL 773 & 7,75 \\
5 & MTL 470 & 8,30 & 16 & MTL 834 & 7,45 \\
6 & MTL 568 & 8,00 & 17 & MTL 856 & 7,30 \\
7 & MTL 579 & 8,00 & 18 & MTL 857 & 7,80 \\
8 & MTL 591 & 7,60 & 19 & MTL 859 & 7,30 \\
9 & MTL 660 & 8,00 & 20 & MTL 883 & 7,40 \\
10 & MTL 684 & 7,60 & 21 & MTL 889 & 7,65 \\
11 & MTL 685 & 7,35 & 22 & IR29 & \\
\hline
\end{tabular}




\subsection{Kết quả đo hàm lượng amylose}

Trong hạt gạo xay, đặc điểm nấu ăn bị ảnh hưởng bởi tỷ lệ của hai loại tinh bột, amylose và amylopectin chứa trong phôi nhũ của hạt gạo (Juliano, 1979). Hàm lượng amylose được phân thành 5 nhóm như sau: Nếp $(0-2 \%)$, rất thấp $(3$ $12 \%)$, thấp $(13-20 \%)$, trung bình $(21-25 \%)$, và cao (> 25\%) (IRRI, 1996). Ở các quốc gia trồng lúa trên thế giới, người tiêu dùng thường chọn các giống lúa có hàm lượng amylose ở mức trung bình (Nguyễn Ngọc Đệ, 2008). Hàm lượng amylose của 20 giống lúa được chia làm 2 nhóm: Nhóm có hàm lượng amylose thấp từ 13 đến $20 \%$ có 6 giống gồm MTL 470, MTL 772, MTL 834, MTL 856, MTL 859 và MTL 883 . Các giống còn lại thuộc nhóm có hàm lượng amylose trung bình từ 21 đến $25 \%$ được thể hiện qua Bảng 4.

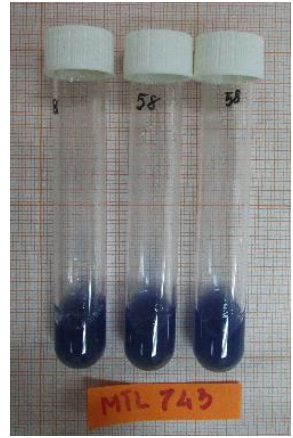

A

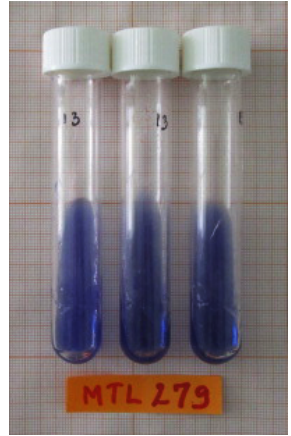

B

\section{3. Độ bền gel}

Ngoài hàm lượng amylose thì độ bền gel cũng là chỉ tiêu quan trọng đánh giá chất lượng cho các giống lúa. Độ bền gel thể hiện độ mềm dẻo của cơm và cơm để nguội. Kết quả đánh giá trên 20 giống lúa cải tiến (Bảng 4 và Hình 1) đã chia được 3 nhóm: Nhóm 1 thuộc cấp cứng cơm có chiều dài thể gel từ $34-40$ mm gồm có 7 giống MTL 591, MTL 743, MTL 772, MTL 773, MTL 857, MTL 883 và MTL 889. Nhóm 2 thuộc cấp trung bình có chiều dài thể gel dao động từ 48 đến $59 \mathrm{~mm}$ gồm có 8 giống. Nhóm 3 là các giống thuộc nhóm mềm cơm có chiều dài thể gel từ 60 đến $82 \mathrm{~mm}$ có 5 giống MTL 232, MTL 421, MTL 470, MTL 579 và MTL 834 các giống này thường được thị trường ưa chuộng vì khi nấu sẽ cho cơm mềm.

\section{Hình 1. Cấp độ bền gel đặc trưng cho 20 giống lúa cải tiến (A: Phân cấp cứng, B: Phân cấp trung bình, $C$ : Phân cấp mềm)}

\subsection{Mùi thơm}

Mùi thơm là một đặc tính vô cùng quan trọng đối với các giống lúa bởi thị hiếu người tiêu dùng hiện nay ngày càng cao, đòi hỏi ăn không chỉ ngon mà còn phải thơm kích thích khẩu vị để bữa ăn được ngon hơn. Do đó, hiện nay đã có nhiều phương pháp thử mùi thơm cũng như gene thơm trên lúa, nhưng phương pháp thử mùi thơm bằng $\mathrm{KOH} 1,7 \%$ cho kết quả nhanh và đánh giá sơ bộ được các giống có mùi thơm để tiếp tục phân tích bằng các kỹ thuật khác. Áp dụng phương pháp $\mathrm{KOH} 1,7 \%$ trên 20 giống lúa cải tiến đã ghi nhận được 18 giống có mùi thơm, trong đó có 11 giống thơm cấp 2 (thơm) và 7 giống thơm cấp 1 (thơm nhẹ) (Bảng 4), chỉ có 2 giống MTL 743 và MTL 834 là không thơm và 2 giống đối chứng Đốc Phụng và IR29 cũng không có mùi thơm.

Cùng với đó là phân tích kiểu gene $f g r$ nằm trên nhiễm sắc thể số 8 kiểm soát tổng hợp chất 2 acetyl- 1-pyrroline (2AP) tạo mùi thơm trên lúa do đã xảy ra các đột biến ở trình tự $\mathrm{BADH} 2$ liên quan đến mùi thơm bao gồm sự mất đoạn 8 bp và ba đa hình nucleotide đơn (SNP) ở exon 7 , kèm theo đó là sự mất đoạn 7 bp ở exon 2 nên tạo mùi thơm $2 \mathrm{AP}$ (Bradbury et al., 2005). Dựa vào đó, Bradbury et al. (2005) đã thiết kế 4 đoạn mồi ESP, EAP, INSP và IFAP tạo ra 3 sự bắt cặp với 3 kích thước khác nhau, cụ thể là cặp mồi ESP và EAP sẽ kết hợp tạo ra band có kích thước 580 bp để nhận diện vùng gene $\mathrm{BADH} 2$, thứ 2 là cặp mồi $\mathrm{EAP}$ - INSP bắt cặp với vùng gene bình thường không có mùi thơm với kích thước $355 \mathrm{bp}$, cuối cùng cặp mồi ESP-IFAP tạo sự bắt cặp với kích thước 257 bp nhận diện kiểu gene bị đột biến tạo mùi thơm 2AP. Kết quả Hình 2 phổ điện di sản phẩm PCR với mồi $\mathrm{BADH} 2$ nhận diện kiểu gene $f g r$ của 20 giống lúa cải tiến trên gel agarose $2 \%$, có 18 giống mang kiểu gene đột biến xuất hiện 2 band hình ở vị trí 580 bp và 257 bp cho 
kết quả thơm, còn lại 2 giống ở vị trí số 13 và 16 (MTL 743 và MTL 834) không mang kiểu gene đột biến nên không tạo mùi thơm $2 \mathrm{AP}$ xuất hiện 2 band hình có kích thước 580 bp và 355 bp, 2 giống đối chứng Đốc Phụng và IR29 cũng không mang kiểu gene đột biến mùi thơm $2 \mathrm{AP}$. Kết quả phân tích kiểu gene và phân tích mùi thơm $\mathrm{KOH} 1,7 \%$ đều cho kết quả giống nhau $100 \%$.

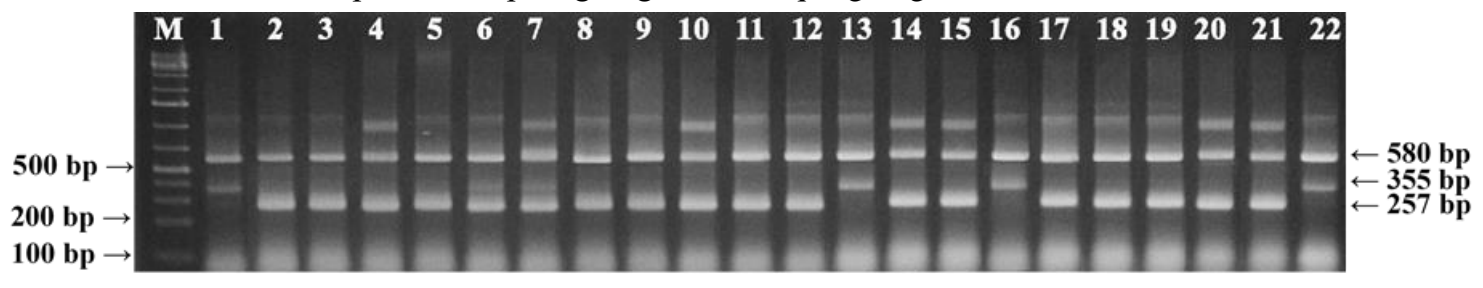

Hình 2. Phổ điện di với mồi BADH2 nhận diện kiểu gene fgr của 20 giống lúa cải tiến trên gel agarose 2\%

Bảng 4. Kết quả đo hàm lượng amylose của 20 giống lúa được nghiên cứu

\begin{tabular}{|c|c|c|c|c|c|c|}
\hline STT & Tên giống & Amylose (\%) & Phân nhóm & Độ bền gel $(\mathrm{cm})$ & Phân cấp & Thơm cảm quan (cấp) \\
\hline 1 & Đốc Phụng & & & & & 0 \\
\hline 2 & MTL232 & 23,4 & Trung bình & 73,33 & Mềm & 1 \\
\hline 3 & MTL279 & 23,0 & Trung bình & 50,00 & Trung bình & 1 \\
\hline 4 & MTL421 & 22,7 & Trung bình & 82,00 & Mềm & 2 \\
\hline 5 & MTL470 & 18,3 & Thấp & 62,33 & Mềm & 1 \\
\hline 6 & MTL568 & 24,2 & Trung bình & 51,00 & Trung bình & 2 \\
\hline 7 & MTL579 & 24,3 & Trung bình & 60,00 & Mềm & 2 \\
\hline 8 & MTL591 & 24,7 & Trung bình & 39,00 & Cứng & 2 \\
\hline 9 & MTL660 & 24,6 & Trung bình & 51,00 & Trung bình & 2 \\
\hline 10 & MTL684 & 22,1 & Trung bình & 50,00 & Trung bình & 2 \\
\hline 11 & MTL685 & 22,6 & Trung bình & 59,67 & Trung bình & 1 \\
\hline 12 & MTL736 & 22,6 & Trung bình & 48,33 & Trung bình & 1 \\
\hline 13 & MTL743 & 24,5 & Trung bình & 26,67 & Cứng & 0 \\
\hline 14 & MTL772 & 20,5 & Thấp & 39,33 & Cứng & 2 \\
\hline 15 & MTL773 & 24,5 & Trung bình & 34,00 & Cứng & 1 \\
\hline 16 & MTL834 & 18,2 & Thấp & 74,33 & Mềm & 0 \\
\hline 17 & MTL856 & 16,6 & Thấp & 57,33 & Trung bình & 2 \\
\hline 18 & MTL857 & 25,0 & Trung bình & 40,00 & Cứng & 2 \\
\hline 19 & MTL859 & 17,6 & Thấp & 57,33 & Trung bình & 2 \\
\hline 20 & MTL883 & 20,8 & Thấp & 35,00 & Cứng & 1 \\
\hline 21 & MTL889 & 22,3 & Trung bình & 34,67 & Cứng & 2 \\
\hline 22 & IR29 & & & & & 0 \\
\hline
\end{tabular}

\subsection{Kết quả đánh giá kiểu gene chịu mặn}

Trong nghiên cứu đánh giá kiểu gene chống chịu mặn, giống lúa được sử dụng làm đối chứng chống chịu là Đốc Phụng được đánh số thứ tự là 1 và giống đối chứng mẫn cảm là giống IR29 được đánh số thứ tự 22 .

Cặp mồi RM286 nằm trên nhiễm sắc thể 11 liên kết với QTL qSNC11 (Hình 3) thể hiện khả năng đào thải $\mathrm{Na}^{+}$trong chồi. Việc đào thải tốt sẽ làm giảm được nồng độ $\mathrm{Na}^{+}$trong chồi, giúp cây có khả năng chịu mặn tốt hơn (Wang et al., 2012). Kết quả phổ điện di mồi RM286, không có sự khác nhau về kiểu gene của 2 giống chuẩn chống chịu và chuẩn mẫn cảm cả 2 đều xuất hiện band có kích thước 115 bp, tuy nhiên có 4 giống MTL xuất hiện band có kích thước 120 bp là số $6,9,17$ và 18 (MTL 568, MTL 660 , MTL 856 và MTL 859) và có 3 giống số 5,13 và số 16 (MTL 470, MTL 743 và MTL 834) mang kiểu gene dị hợp. Điều này thể hiện sự khác biệt về kiểu gene của 4 giống MTL trên so với kiểu gene 2 giống chuẩn chống chịu và chuẩn mẫn cảm về sự đào thải $\mathrm{Na}^{+}$trong chồi. 


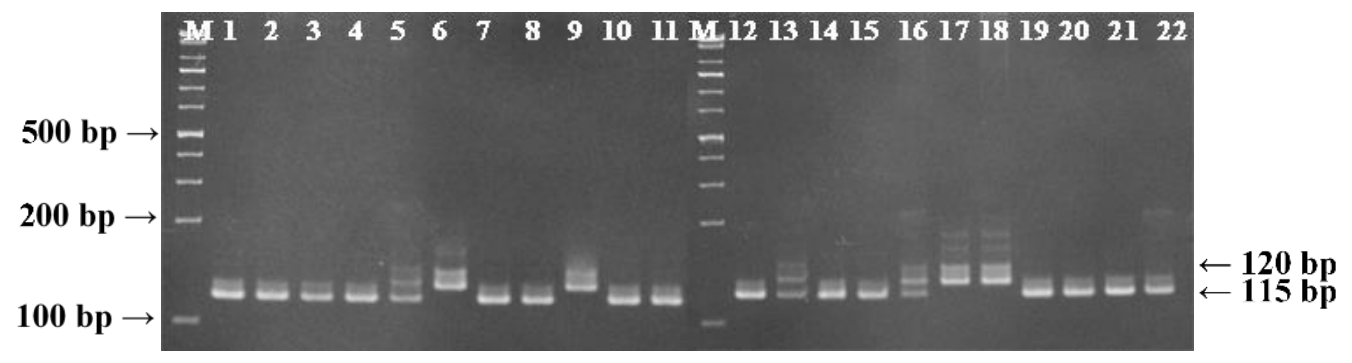

Hình 3. Phổ điện di với mồi RM286 nhận diện kiểu gene kháng mặn trên nhiễm sắc thể số của 20 giống lúa cải tiến trên gel acrylamide $8 \%$

Trên nhiễm sắc thể số 10 ứng với cặp mồi RM474 liên kết với QTL SalTol10-1 (Islam et al., 2011; Thomson et al., 2010) khuếch đại được 2 band hình trên chuẩn chống chịu (Đốc Phụng) với kích thước 285 và $345 \mathrm{bp}$, và 2 band hình đối với giống chuẩn mẫn cảm (IR29) với kích thước 215 và 260 bp. Dựa vào đó nhận diện được 3 giống MTL mang kiểu gene tương đồng với giống Đốc Phụng là các giống số 4,13 và 19 (MTL 421, MTL 743 và MTL 859), tất cả các giống còn lại đều mang kiểu gene tương đồng với giống IR29.

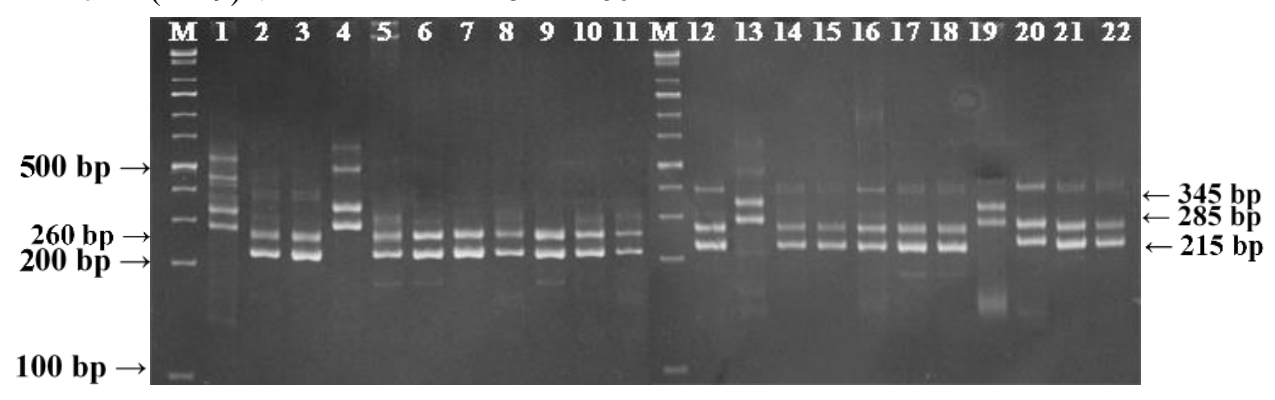

Hình 4. Phổ điện di với mồi RM474 nhận diện kiểu gene kháng mặn trên nhiễm sắc thể số của 20 giống lúa cải tiến trên gel acrylamide $8 \%$

Tương tự ở nhiễm sắc thể số 3 tương ứng với cặp mồi RM6329 giống Đốc Phụng cho kiểu gene đồng hợp tử trội có kích thước khoảng 145 bp, còn giống IR29 cho kiểu hình đồng hợp tử lặn có kích thước khoảng $125 \mathrm{bp}$. Với mồi này, chỉ có 1 giống lúa MTL 232 mang kiểu gene tương đồng với giống Đốc Phụng, cùng với đó là có 2 giống mang kiểu gene dị hợp tử là MTL 736 và MTL 773, còn lại các giống mang kiểu gene giống với giống chuẩn mẫn cảm IR29. So với kết quả nghiên cứu trước đây, cặp mồi RM6329 liên kết với QTL $q C H L 3$ thể hiện khả năng quang hợp của lá khi gặp điều kiện mặn (Thomson et al., 2010). Như vậy, kết quả trên cho thấy giống Đốc Phụng và MTL 232 có band hình ở kích thước 145 bp mang kiểu gene thể hiện khả năng quang hợp tốt hơn các giống còn lại có band hình 125 bp trong điều kiện mặn (Hình 3).

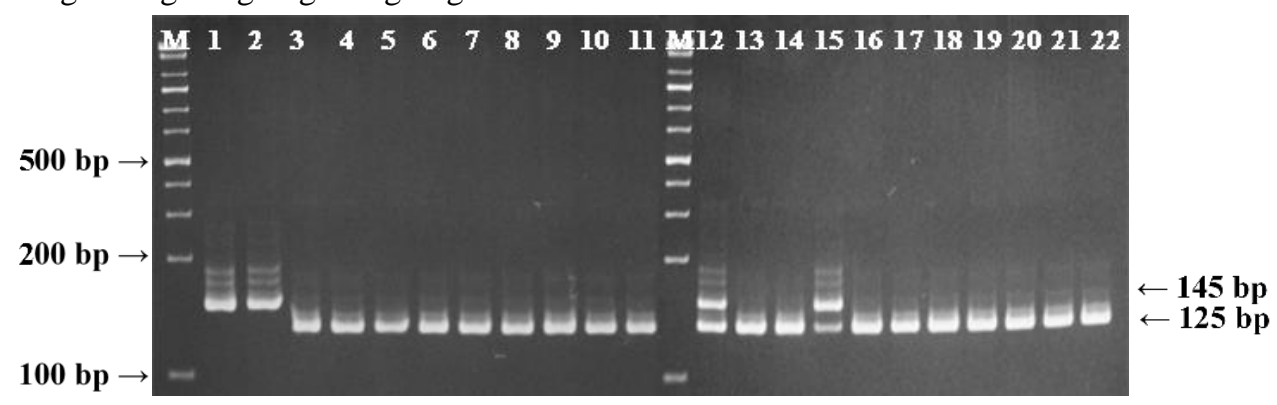

Hình 5. Phổ điện di với mồi RM6329 nhận diện kiểu gene kháng mặn trên nhiễm sắc thể số của 20 giống lúa cải tiến trên gel acrylamide $8 \%$ 
Đối với cặp mồi RM6369 liên kết với QTL qTN8.1 nằm trên NST số 8 (Hình 6) liên quan đến sự phát triển trong điều kiện mặn (Lin et al., 2004), kết quả nhận diện được các giống chống chịu và giống mẫn cảm qua 2 giống Đốc Phụng và IR29 với kích thước lần lượt là 120 bp và 110 bp. Với các giống mang kiểu gene chống chịu giống với Đốc Phụng là giống số $5,6,7,12,14$ và 21 (MTL 470, MTL 568, MTL 579, MTL 736, MTL 772 và MTL889), các giống còn lại có kiểu gene giống với IR29.

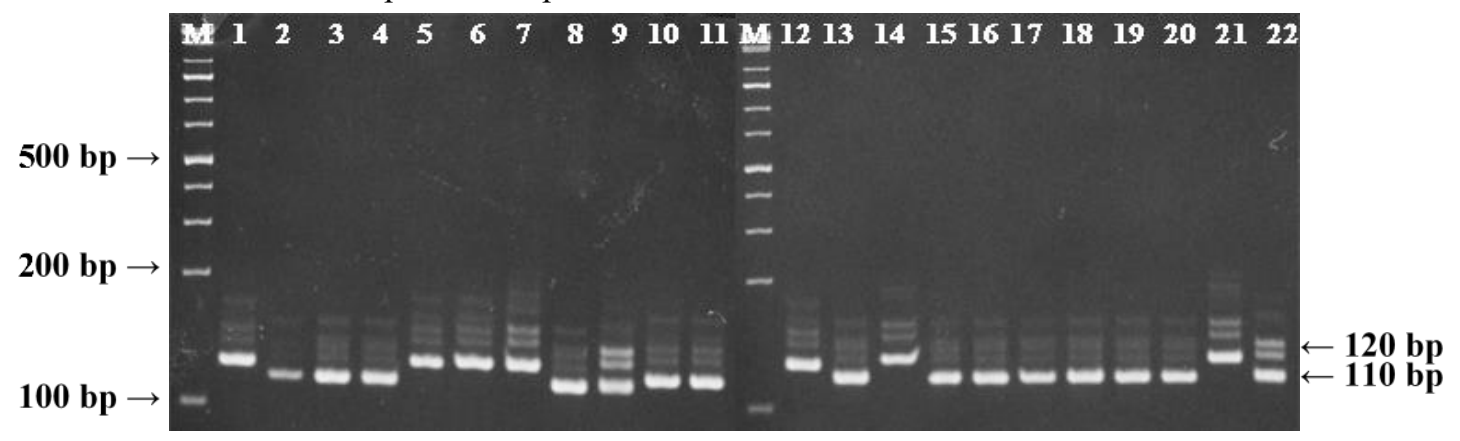

\section{Hình 6. Phổ điện di với mồi RM6369 nhận diện kiểu gene kháng mặn trên nhiễm sắc thể số của 20 giống lúa cải tiến trên gel acrylamide $8 \%$}

Theo Thomson et al. (2010), cặp mồi RM24330 nằm trên nhiễm sắc thể số 9 và liên kết trên hai QTL rất quan trọng trong việc hình thành tính chống chịu mặn là $q S N K 9$ và $q R N K 9$ (Hình 7). Đây là hai QTL thể hiện sự hấp thụ cũng như tích lũy $\mathrm{K}^{+}$cao và tỷ lệ $\mathrm{K}^{+} / \mathrm{Na}^{+}$cao trên giống lúa chống chịu mặn. Dựa vào 2 đối chứng chống chịu và mẫn cảm cho thấy được giống chống chịu sẽ có kích thước band ở vị trí 95 bp và đối với giống mẫn cảm là 110 bp. Như vậy, kết quả điện di sản phẩm PCR với mồi RM24330 nhận diện được các giống vị trí số 4, 11 và 15 (MTL 421, MTL 685 và MTL 773) là có kiểu gene giống với giống chống chịu Đốc Phụng ở vị tri số 1, riêng giống ở vị trí số 13 (MTL 743) mang gene dị hợp tử, tất cả các giống còn lại đều mang kiểu gene giống với giống mẫn cảm IR29 vị trí số 22 .

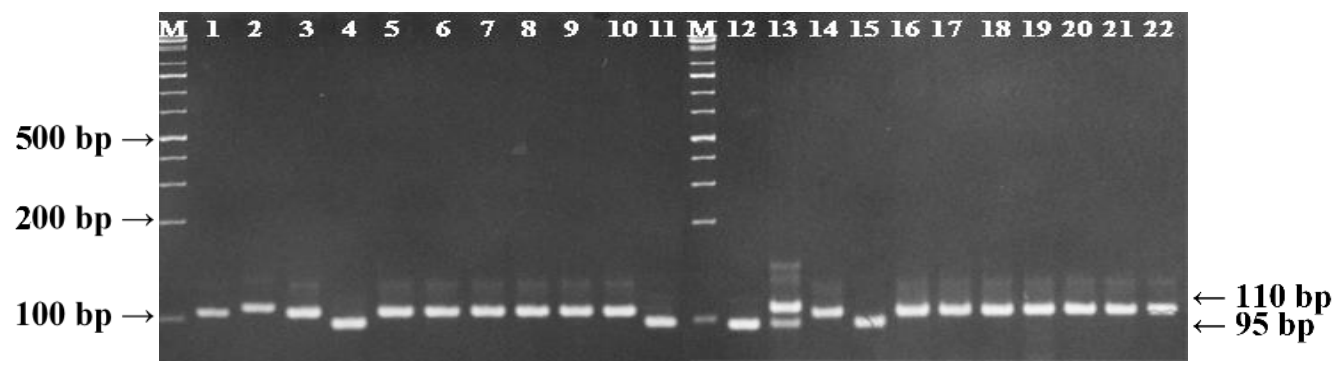

Hình 7. Phổ điện di với mồi RM24330 nhận diện kiểu gene kháng mặn trên nhiễm sắc thể số của 20 giống lúa cải tiến trên gel acrylamide $8 \%$

Qua kết quả phân tích sử dụng phương pháp UPGMA thông qua phần mềm NTSYS pc 2.1 để tạo nên sơ đồ phân nhóm của 20 giống lúa cải tiến cùng với giống Đốc Phụng và giống IR29 bằng 12 cặp mồi SSR liên kết với QTL chịu mặn ở trên 12 NST (Hình 8), các giống lúa được chia thành 3 nhóm chính. Nhóm I gồm 1 giống Đốc Phụng có khoảng cách nằm trong khoảng 0,49 so với tất cả 20 giống lúa được nghiên cứu. Nhóm II gồm có 17 giống MTL và 1 giống IR29, kết hợp với phân tích kiểu gene dựa vào 12 cặp mồi SSR liên kết với 12 NST nhận thấy các giống MTL có kiểu gene tương đồng với giống IR29 với khoảng cách tương đồng là 0,81 đến 1,00 . Điều này chứng tỏ 17 giống MTL không có khả năng chống chịu trong điều kiện mặn như giống IR29. Nhóm III gồm có 3 giống MTL 421, MTL 743 và MTL 859 có sự khác biệt so với các giống còn lại có hệ số tương đồng $(0,49-0,67)$ gần với giống Đốc Phụng, từ đó có thể thấy 3 giống MTL này có triển vọng trong khả năng chống chịu với điều kiện mặn, với kết quả này làm tiền đề tiếp theo cho nghiên cứu thanh lọc mặn. 


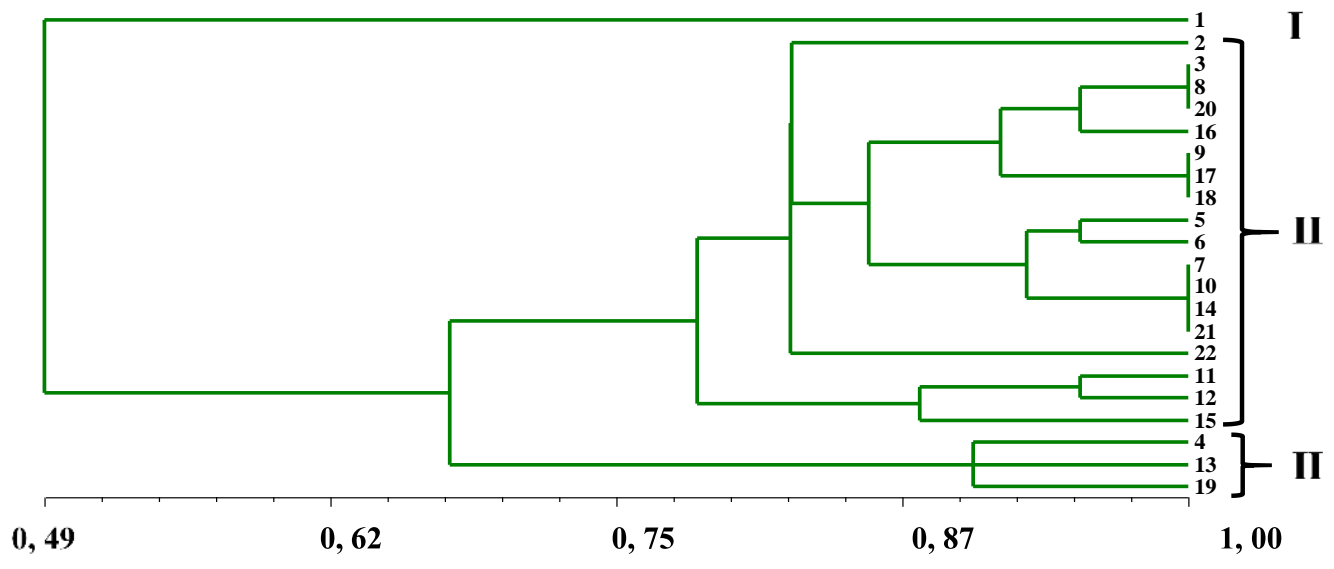

Hình 8. So đồ di truyền nhánh dựa trên dấu phân tử SSR của 20 giống lúa cải tiến phân tích hệ số tương đồng Nei-Li bằng phương pháp UPGMA

\section{KẾT LUẬn VÀ ĐỀ XUẤT}

\subsection{Kết luận}

Qua kết quả nghiên cứu, 3 giống ưu tú về kiểu gene chống chịu mặn, có dạng hạt thon dài đã được lựa chọn. Hàm lượng amylose thấp ở giống MTL 859 , và hàm lượng amylose trung bình ở giống MTL 421 và MTL 743, phù hợp với nhu cầu thị hiếu của người tiêu dùng. Trong 3 giống được chọn, 2 giống mang kiểu gene thơm và có mùi thơm cấp 2 bằng phương pháp $\mathrm{KOH} 1,7 \%$.

\section{2. Đề xuất}

Việc thử nghiệm mặn với các giống mang gene chống chịu là cần thiết, bên cạnh đó tiếp tục nghiên cứu đánh giá thêm nhiều dấu chỉ thị phân tử khác.

\section{LỜI CẢM TẠ}

Nghiên cứu được tài trợ bởi dự án Nâng cấp Trường Đại học Cần Thơ VN14-P6 (vốn vay ODA từ chính phủ Nhật Bản). Chân thành cám ơn quý Thầy Cô của Viện nghiên cứu và Phát triễn ĐBSCL đã cung cấp vật liệu nghiên cứu.

\section{TÀI LIỆU THAM KHẢO}

Bonilla, P., Dvorak, J., Mackill, D., Deal, K. \& Gregorio, G. (2002). RFLP and SSLP mapping of salinity tolerance genes in chromosome 1 of rice (Oryza sativa L.) using recombinant inbred lines. Philippine Journal of Agricultural Science, 85, 68-76.

Bradbury, L. M. T., Fitzgerald, T. L., Henry, R. J., Jin, Q. S., \& Waters, D. L. E. (2005). The gene for fragrance in rice. Plant Biotechnol. J., 3(3), 363-370. https://doi.org/10.1111/j.14677652.2005.00131.x
Doyle, J. J., \& Doyle, J. L. (1990). Isolation of plant DNA from fresh tissue. Focus, 12(1),13-15.

Ganie, S. A., Molla, K. A., Henry, R. J., Bhat, K. V., \& Mondal, T. K. (2019). Advances in understanding salt tolerance in rice. Theor Appl Genet, 132, 851-870. https://doi.org/10.1007/s00122-019-03301-8

Graham, R. (2002). A Proposal for IRRI to Establish a Grain Quality and Nutrition Research Center. IRRI Discussion Paper Series. Los Baños (Philippines): International Rice Research Institute., 4, 15.

IRRI. (1980). Descriptions for rice Oryza sativa. International Rice Research Institute, Los Baños, Philippines (in press): $21 \mathrm{p}$.

IRRI. (1996). Standard evaluation system for rice. International rice Research Institute, P.O.Box.933.1099 Manila, Philippines.

Islam, F., Wang, J., Farooq, M. A., Khan, M. S. S., Xu, L., Zhu, J., Zhao, M., Muños, S., Li, Q. X., \& Zhou, W. (2018). ZhouPotential impact of the herbicide 2,4- dichlorophenoxyacetic acid on human and ecosystems. Environment International, 111, 332-351. https://doi.org/10.1016/j.envint.2017.10.020

Islam, M. R., Salam, M. A., Hassan, L., Collard, B. C. Y., Singhand, R. K., \& Gregorio, G. B. (2011). QTL mapping for salinity tolerance at seedling stage in rice. Emir. J. Food Agric., 23(2), 137-146. https://doi.org/10.9755/ejfa.v23i2.6348

Istvan Lazar Jr., P., and Istvan Lazar Sr., PhD. (2019). GelAnalyzer (Version 19.1). Retrieved from http://www.gelanalyzer.com/index.html

Juliano, B. O. (1979). Amylose analysis in rice-A review. In: Proc. Workshop on Chemical Aspects 
of Rice Grain Quality. IRRI: Los Bafnos, Laguna, Philippines.

Kurotani, K., Yamanaka, K., Toda, Y., Ogawa, D., Tanaka, M., Kozawa, H., Nakamura, H., Hakata, M., Ichikawa, H., Hattori, T., \& Takeda, S. (2015). Stress Tolerance Profiling of a Collection of Extant Salt-Tolerant Rice Varieties and Transgeneic Plants Overexpressing Abiotic Stress Tolerance Genes. Plant and cell physiology, 56(10), 1867-76. https://doi.org/10.1093/pcp/pcv106

Lin, H. X., Zhu, M. Z., Yano, M., Gao, J. P., Liang, Z. W., Su, W. A., Hu, X. H., Ren, Z. H., \& Chao, D. Y. (2004). QTLs for Na+ and K+ uptake of the shoots and roots controlling rice salt tolerance. Theoretical and Applied Genetics, 108(2), 253-260. https://doi.org/10.1007/s00122003-1421-y

Mitchell, C. H., Richard, G. S., Meagan, E. S., Lesley, W. A., \& David, A. M. (2017). Agriculture in 2050: Recalibrating Targets for Sustainable Intensification. BioScience, 67, 386391. https://doi.org/10.1093/biosci/bix010

Mohammadi-Nejad, G., Arzani, A., Rezai, A. M., Singh, R. K., \& Gregorio, G. B. (2008). Assessment of rice geneotypes for salt tolerance using microsatellite markers associated with the saltol QTL. African Journal of Biotechnology, 7(6), 730-736.

Nguyễn Ngọc Đệ. (2008). Giáo trình cây lúa. Nhà xuất bản Đại học Quốc gia Thành phố Hồ Chí Minh.

Qin, H., Li, Y., \& Huang, R. (2020). Advances and Challenges in the Breeding of Salt-Tolerant Rice. International Journal of Molecular Sciences., 21(21), 8385. https://doi.org/10.3390/ijms21218385
Thomson, M. J., Ocampo, M. D, Egdane, J., Rahman, M. A., Sajise, A. G., Adorada, D. L., Tumimbang-Raiz, E., Blumwald, E., Seraj, Z. I., Singh, R. K., Gregorio, G. B., \& Ismail, A. M. (2010). Characterizing the Saltol quantitative trait locus for salinity tolerance in rice. Rice, 3(2), 148 - 160. https://doi.org/10.1007/s12284010-9053-8

Wang, Z., Chen, Z., Cheng, J., Lai, Y., Wang, J., Bao, Y., Huang, J., \& Zhang, H. (2012). QTL Analysis of $\mathrm{Na}+\& \mathrm{~K}+$ Concentrations in Roots $\&$ Shoots under Different Levels of $\mathrm{NaCl}$ Stress in Rice (Oryza sativa L.). PLoS ONE, 7(12), 1537-1545. doi:10.1371/journal.pone.0051202. https://doi.org/10.1371/journal.pone.0051202

Wu, F., Yang, J., Yu, D., \& Xu, P. (2020). Identification and Validation a Major QTL from "Sea Rice 86" Seedlings Conferred Salt Tolerance. Agronomy, 10, 410. https://doi.org/10.3390/agronomy10030410

Yadav, A. K., Kumar, A., Grover, N., Ellur, R. K., Krishnan, S. G., Bollinedi, H., Bhowmick, P. K., Vinod, K. K., Nagarajan, M., Krishnamurthy, S. L., \& Singh, A.K. (2020). Marker aided introgression of 'Saltol', a major QTL for seedling stage salinity tolerance into an elite Basmati rice variety 'Pusa Basmati 1509'. Scientific reports, 10(1), 13877. https://doi.org/10.1038/s41598-020-70664-0.

Zhao, F., \& Zhang, H. B. (2007). Transgeneic rice breeding for abiotic stress tolerance--present \& future. Sheng wu gong cheng xue bao Chinese journal of biotechnology, 23(1), 1-6. https://doi.org/10.1016/S1872-2075(07)60001-6 